\title{
Risk factors for complete recovery of adults after weaning from veno-venous extracorporeal membrane oxygenation for severe acute respiratory failure: an analysis from adult patients in the Extracorporeal Life Support Organization registry
}

Hye Ju Yeo ${ }^{1}$, Yun Seong Kim', Dohyung Kim², ELSO Registry Committee ${ }^{3}$ and Woo Hyun Cho ${ }^{\text {** }}$

\begin{abstract}
Background: As extracorporeal membrane oxygenation (ECMO) has been widely used, the patient quality of life following ECMO termination has become an important issue as same as the patient's survival. To date, the factors affecting complete recovery of adult survivors from ECMO have not been investigated.

Methods: Data from adult patients in the Extracorporeal Life Support Organization registry who received venovenous ECMO between 2012 and 2017 were analyzed. Multivariate logistic regression analyses were conducted.

Results: In total, 6536 patients with 242,183 days of veno-venous ECMO were reviewed. The overall survival to discharge rate after weaning from ECMO was $89.7 \%(n=5861)$, and 10.3\% $(n=675)$ of the patients died during hospitalization. The discharge location varied as follows: $33.7 \%(n=1976)$ returned home, $23.4 \%(n=1369)$ were transferred to a referral hospital, $41.8 \%(n=2447)$ required hospital services, and $0.6 \%(n=36)$ were discharged to other places. The patients were divided into two groups according to the discharge location: a complete recovery group $(n=1976)$ and a partial recovery group $(n=3885)$. In the multivariate analyses, age ( $\geq 65$ years) (odds ratio (OR) $0.72,95 \%$ confidence interval $(C l) 0.59-0.87, p=0.001$ ), cardiac arrest before ECMO (OR 0.76, 95\% Cl 0.60-0.96, $p=0.021$ ), vasopressor use (OR $0.73,95 \% \mathrm{Cl} 0.64-0.83, p<0.001)$, renal replacement therapy (OR $0.40,95 \% \mathrm{Cl} 0.28-$ $0.57, p<0.001$ ), ECMO-related complications (OR 0.76, 95\% Cl 0.67-0.85, $p<0.001$ ), and long-term ECMO support ( $\geq 2$ weeks) (OR $0.42,95 \% \mathrm{Cl} 0.37-0.48, p<0.001$ ) were significantly associated with complete recovery.
\end{abstract}

\footnotetext{
* Correspondence: chowh@pusan.ac.kr

'Division of Pulmonary, Allergy, and Critical Care Medicine, Department of Internal Medicine, Pusan National University Yangsan Hospital, Geumo-ro 20, Beomeo-ri, Mulgeum-eup, Yangsan-si, Gyeongsangnam-do 626-770, Republic of Korea

Full list of author information is available at the end of the article
}

(c) The Author(s). 2020 Open Access This article is licensed under a Creative Commons Attribution 4.0 International License, which permits use, sharing, adaptation, distribution and reproduction in any medium or format, as long as you give appropriate credit to the original author(s) and the source, provide a link to the Creative Commons licence, and indicate if changes were made. The images or other third party material in this article are included in the article's Creative Commons licence, unless indicated otherwise in a credit line to the material. If material is not included in the article's Creative Commons licence and your intended use is not permitted by statutory regulation or exceeds the permitted use, you will need to obtain permission directly from the copyright holder. To view a copy of this licence, visit http://creativecommons.org/licenses/by/4.0/. The Creative Commons Public Domain Dedication waiver (http://creativecommons.org/publicdomain/zero/1.0/) applies to the data made available in this article, unless otherwise stated in a credit line to the data. 
(Continued from previous page)

Conclusion: Complete recovery after veno-venous ECMO support is associated with the patient's baseline condition, ECMO duration, and ECMO-related complications. Respiratory ECMO should aim to increase both the survival and the quality of life after weaning from ECMO.

Keywords: Extracorporeal membrane oxygenation, Survival, Recovery, Complications

\section{Introduction}

Survivors of acute respiratory distress syndrome (ARDS) often experience mental, physical, social, and functional impairments following hospital discharge [1-3]. In previous studies, a substantial discrepancy between survival to discharge and long-term survival after ARDS was observed, and late mortality was increased by age and comorbidities, not the initial severity of the ARDS $[4,5]$. Since then, many studies have focused on the quality of life of ARDS survivors [6-9].

ECMO is recommended for the most severe form of ARDS as a lifesaving treatment. It is clear that this subset of patients will experience the sequelae of ARDS and critical illness, but data is lacking. In a previous multicenter cohort study of respiratory ECMO, $25.7 \%$ of the patients died in hospital after weaning from ECMO, and a further $6.9 \%$ died in the first 6 months following hospital discharge [10]. A substantial proportion of patients experienced significant unexpected re-exacerbation of ARDS after weaning from ECMO and were at risk of physical, functional, and psychological complications [11-14]. Accordingly, as same as the patient's survival, the patient's quality of life after ECMO termination has become an important issue as its use has increased. Understanding the outcome after ECMO weaning and identifying the risk factors affecting complete recovery are crucial for the improvement of the long-term outcome of ECMO support. There have been several studies of the factors associated with mortality after weaning from ECMO, but the focus was not on complete recovery [15-17]. In this study, we evaluated the unfavorable factors for complete recovery of adults after weaning from veno-venous (VV) ECMO for severe acute respiratory failure.

\section{Materials and methods}

The study design and data protection methods were presented to the Extracorporeal Life Support Organization (ELSO) steering committee, which allowed us to conduct a retrospective analysis of the ELSO registry data. This voluntary database collects baseline and outcome data on patients undergoing ECMO treatment in participating centers, with a total of 784 centers contributing until 2017. The data include age, sex, weight, primary and other diagnoses, discharge location, basic ventilation data, hemodynamic variables, arterial blood gas results, and clinical outcomes, including ECMO complications. All VV ECMO records between the years 2012 and 2017 were extracted from the ELSO database, excluding those for pediatric and neonatal patients, patients on venoarterial ECMO $(n=13,034)$. For the analysis of the postweaning outcomes, we excluded patients who were discharged with ECMO $(n=22)$ and those who died while receiving $\mathrm{ECMO}(n=5506)$. The other exclusion criteria included multiple ECMO runs, where ECMO was used as a bridge to transplantation, and unknown discharge location $(n=970)$. Missing data were not imputed. Postweaning outcomes were presented as survival to discharge or death. Survivors were classified into two groups, namely, complete recovery or partial recovery, depending on the discharge location. The complete recovery (CR) group comprised patients who were discharged to home, whereas the partial recovery (PR) group comprised patients who required hospital services, were transferred to a referral hospital, or were discharged to other places (Fig. 1). The analysis was approved by the institutional review board (Pusan National University Yangsan Hospital, 05-2019-135), and the need for informed consent was waived.

\section{Statistical analyses}

Continuous variables were examined for normality using the Shapiro-Wilk test. Normally distributed variables were compared using the Student's $t$ test, whereas nonnormally distributed variables were compared using the Kruskal-Wallis test. Categorical variables were examined using Fisher's exact test or the chi-squared test. A value of $p<0.05$ was defined as statistically significant. To evaluate the factors associated with $\mathrm{CR}$ after weaning from ECMO, logistic regression analysis was conducted. All potential clinical factors were evaluated using univariate analysis, and multivariate logistic regression analysis was conducted for variables with $p$ value $<0.05$. The backward stepwise method was used for multivariate analysis, with entry and removal $\mathrm{p}$ values set at 0.05 . Statistical analysis was performed using the R software ( $\mathrm{R}$ Foundation for Statistical Computing, Vienna, Austria, 2014).

\section{Results}

In total, 6536 patients with 242,183 days of VV ECMO were analyzed (Fig. 1). The overall survival to discharge rate after weaning from ECMO was $89.7 \%(n=5861)$, 


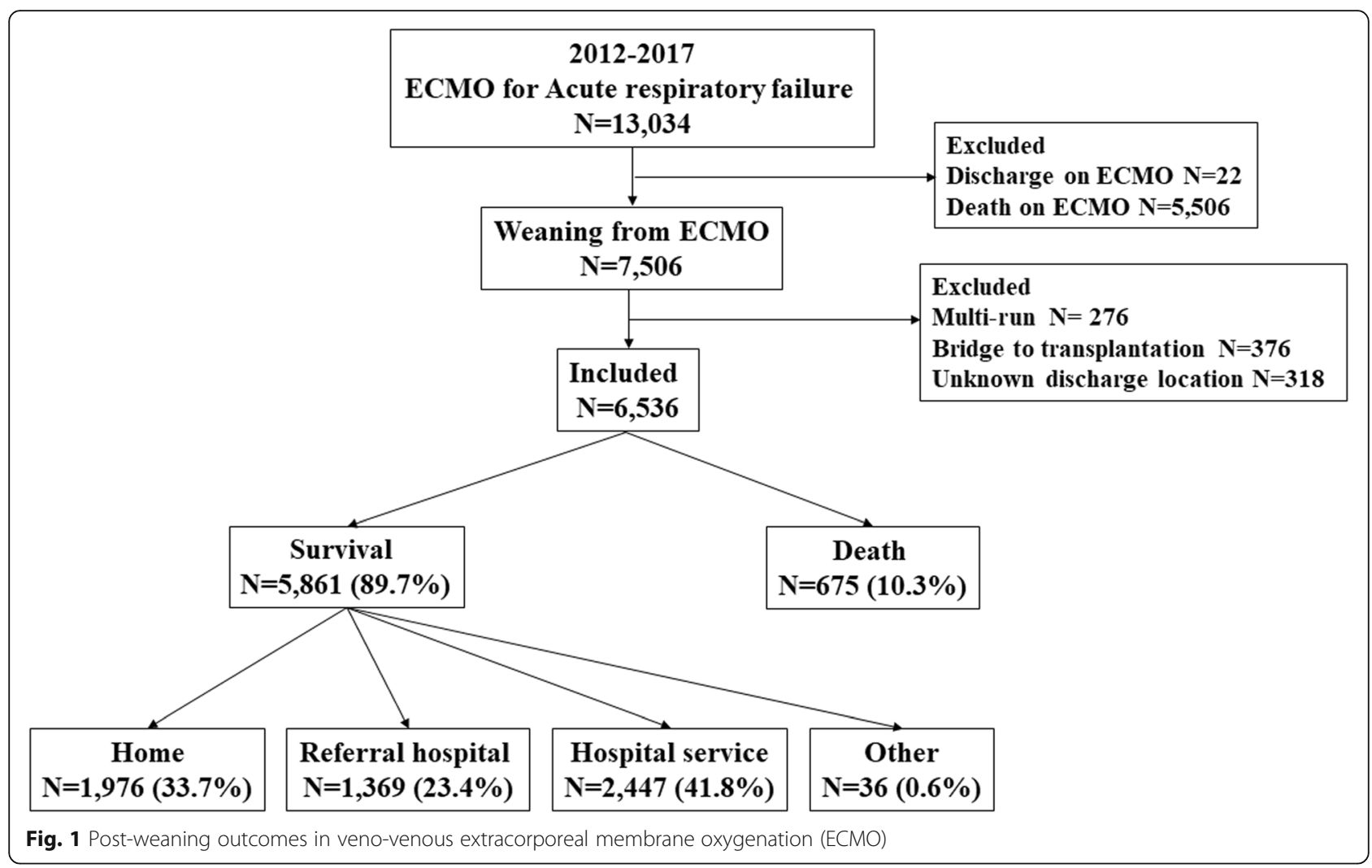

and $10.3 \%(n=675)$ of the patients died during hospitalization. The discharge location varied as follows: $33.7 \%(n=1976)$ returned home, $23.4 \%(n=1369)$ were transferred to a referral hospital, $41.8 \%(n=2447)$ required hospital services, and $0.6 \%(n=36)$ were discharged to other places. The patients were divided into two groups: the CR group $(n=1976)$ and the PR group $(n=3885)$.

\section{Baseline characteristics and rescue therapy before ECMO initiation}

Summary characteristics are presented and compared between the groups in Table 1. Significant differences in sex, age, and body weight were observed when the CR group was compared with the PR group (males $57.3 \%$ vs $60.9 \%, p=0.009$; mean age 42.3 vs 45.9 years, $p<0.001$; mean body weight 85.9 vs $91.6 \mathrm{~kg} ; p<0.001$ ). The distribution of primary diagnosis was different between two groups $(p<0.001)$. In the CR group, bacterial pneumonia and viral pneumonia were less common (bacterial $1.9 \%$ vs $3.0 \%$, viral $18.1 \%$ vs $25.8 \%, p<0.001)$. The ventilator settings and hemodynamics before ECMO initiation were significantly different between the two groups: the mean peak inspiratory pressure, PF ratio, and arterial blood pressure were higher in the CR group
( $p=0.017, p=0.005$, and $p<0.001$, respectively). Cardiac arrest before ECMO initiation, renal replacement therapy (RRT) use, and a vasopressor requirement were less common in the CR group $(p=0.039, p<0.001$, and $p<0.001$, respectively). The use of rescue therapies before ECMO initiation significantly differed between the CR and PR groups (inhaled NO $11 \%$ vs 9.2\%, $p=0.030$; neuromuscular block (NMB) agent $28.9 \%$ vs $32.3 \%, p=$ 0.009).

\section{Outcomes related to ECMO and post-weaning outcomes}

The clinical outcomes of ECMO are outlined in Table 2. The mean ECMO duration (days) was shorter $(p<$ 0.001 ), and the proportion of long-term ECMO support ( $\geq 2$ weeks) was significantly lower in the CR group ( $p<$ $0.001)$. The rate of ECMO-related complications was significantly lower in the CR group (56.9\% vs $67.7 \%, p<$ 0.001), including cardiovascular, mechanical, neurological, pulmonary, and renal complications (Table 2).

The rates of CR and ECMO complications were inversely related to ECMO duration (Fig. 2). As the ECMO duration increased, the cumulative incidence of ECMO complications increased, but the cumulative proportion of CR decreased. 
Table 1 Baseline characteristics before initiation of extracorporeal membrane oxygenation (ECMO)

\begin{tabular}{|c|c|c|c|}
\hline Variables & $\mathrm{CR}(n=1976)$ & $\operatorname{PR}(n=3885)$ & $p$ \\
\hline Male & $1057(57.3)$ & $2336(60.9)$ & 0.009 \\
\hline Age & $42.3 \pm 15.2$ & $45.9 \pm 14.7$ & $<0.001$ \\
\hline Weight & $85.9 \pm 27.1$ & $91.6 \pm 29.2$ & $<0.001$ \\
\hline \multicolumn{3}{|l|}{ Primary diagnosis } & $<0.001$ \\
\hline Bacterial pneumonia & $38(1.9)$ & $117(3.0)$ & \\
\hline Viral pneumonia & $357(18.1)$ & $1004(25.8)$ & \\
\hline COPD/asthma & $123(6.2)$ & $208(5.4)$ & \\
\hline Interstitial lung disease & $174(8.8)$ & $122(3.1)$ & \\
\hline Trauma and burn & $113(5.7)$ & $218(5.6)$ & \\
\hline ARDS & $656(33.2)$ & $1145(29.5)$ & \\
\hline Aspiration pneumonitis & $15(0.8)$ & $32(0.8)$ & \\
\hline Sepsis & $29(1.5)$ & $69(1.8)$ & \\
\hline Others & $471(23.8)$ & $970(25.0)$ & \\
\hline \multicolumn{4}{|l|}{ Ventilator before ECMO } \\
\hline PIP & $35.1 \pm 10.8$ & $34.2 \pm 9.1$ & 0.017 \\
\hline PEEP & $13.0 \pm 5.5$ & $13.1 \pm 5.7$ & 0.674 \\
\hline $\mathrm{PaO} 2$ FiO2 ratio & $90.8 \pm 107.5$ & $75.7 \pm 188.9$ & 0.005 \\
\hline Mean ABP & $74.7 \pm 19.2$ & $72.2 \pm 16.9$ & $<0.001$ \\
\hline Cardiac arrest before ECMO & $111(5.6)$ & $273(7.0)$ & 0.039 \\
\hline RRT & $38(1.9)$ & $213(5.5)$ & $<0.001$ \\
\hline Vasopressor & $447(22.6)$ & $1186(30.5)$ & $<0.001$ \\
\hline \multicolumn{4}{|l|}{ Rescue therapy before ECMO } \\
\hline Systemic steroids & $158(8.0)$ & $345(8.9)$ & 0.253 \\
\hline NO inhalation & $218(11.0)$ & $359(9.2)$ & 0.030 \\
\hline NMB agents & $572(28.9)$ & $1254(32.3)$ & 0.009 \\
\hline
\end{tabular}

Values are expressed as mean \pm standard deviation or $n(\%)$ COPD chronic obstructive pulmonary disease, ARDS acute respiratory distress syndrome; ECMO extracorporeal membrane oxygenation, PIP peak inspiratory pressure, $P E E P$ positive end expiratory pressure, $A B P$ arterial blood pressure, $R R T$ renal replacement therapy, NO nitric oxide, $N M B$ neuromuscular blockade

\section{Unfavorable factors for CR after weaning from ECMO}

In the univariate analysis, age ( $\geq 65$ years) (OR 0.81, 95\% CI $0.68-0.98, p=0.030)$, cardiac arrest before ECMO (OR 0.79, 95\% CI 0.63-0.99, $p=0.040$ ), vasopressor use (OR 0.67, 95\% CI 0.59-0.75, $p<0.001$ ), neuromuscular blocking agent use (OR 0.86, 95\% CI 0.76-0.96, $p=$ 0.009), RRT (OR 0.34, 95\% CI 0.24-0.48, $p<0.001$ ), ECMO-related complications (OR 0.63, 95\% CI 0.56$0.71, p<0.001)$, and long-term ECMO support $(\geq 2$ weeks) (OR 0.41, 95\% CI 0.36-0.47, $p<0.001$ ) were significantly associated with CR (Table 3 ).

In the multivariate analyses, age ( $\geq 65$ years) (OR 0.72 , 95\% CI 0.59-0.87, $p=0.001)$, cardiac arrest before ECMO (OR 0.76, 95\% CI 0.60-0.96, $p=0.021$ ), vasopressor use (OR 0.73, 95\% CI 0.64-0.83, $p<0.001$ ), RRT (OR 0.40, 95\%
Table 2 Outcomes related to extracorporeal membrane oxygenation (ECMO)

\begin{tabular}{llll}
\hline Variables & CR $(n=1976)$ & $\mathrm{PR}(n=3885)$ & $p$ \\
\hline ECMO duration (days) & $29.8 \pm 34.6$ & $41.1 \pm 43.6$ & $<0.001$ \\
$\begin{array}{l}\text { Long-term ECMO support } \\
(\geq 2 \text { weeks }\end{array}$ & $1362(68.9))$ & $3281(84.5)$ & $<0.001$ \\
ECMO complications & $1125(56.9)$ & $2630(67.7)$ & $<0.001$ \\
Cardiovascular & $523(26.5)$ & $1350(34.7)$ & $<0.001$ \\
Hemorrhage & $362(18.3)$ & $780(20.1)$ & 0.108 \\
Infection & $250(12.7)$ & $557(14.3)$ & 0.077 \\
Limb & $15(0.8)$ & $46(1.2)$ & 0.130 \\
Mechanical & $364(18.4)$ & $907(23.3)$ & $<0.001$ \\
Metabolic & $291(14.7)$ & $633(16.3)$ & 0.120 \\
Neurological & $27(1.4)$ & $139(3.6)$ & $<0.001$ \\
Pulmonary & $115(5.8)$ & $286(7.4)$ & 0.027 \\
Renal & $489(24.7)$ & $1439(37.0)$ & $<0.001$ \\
\hline
\end{tabular}

Values are expressed as mean \pm standard deviation or $n$ (\%) $C R$ complete recovery, $P R$ partial recovery, ECMO extracorporeal membrane oxygenation

CI 0.28-0.57, $p<0.001$ ), ECMO-related complications (OR $0.76,95 \%$ CI $0.67-0.85, p<0.001)$, and long-term ECMO support ( $\geq 2$ weeks) (OR 0.42, 95\% CI 0.37-0.48, $p<0.001$ ) were significantly associated with CR (Fig. 3). The odds ratio of each of the ECMO-related complications for CR is presented in Additional file 1.

\section{Discussion}

This study revealed that only one third of patients returned home, and a substantial proportion of patients required additional hospitalization or hospital services despite surviving to discharge. The age, cardiac arrest before ECMO, severity of organ failure (vasopressor or RRT use), ECMO-related complications, and long-term ECMO support had unfavorable effects on CR. These results indicate that not only the patient's baseline condition but also the ECMO duration and ECMO-related complications are important for CR following ECMO support, and survival does not guarantee CR.

In this study, the proportion of ECMO survivors who required transfer to another hospital or continued hospital services was higher than in other critical care populations [18-20]. The prolonged use of medical services in many survivors implied that a substantial proportion of survivors did not achieve a CR when compared with survivors of other critical illnesses. The long-term prognosis of ARDS in the pre-ECMO era is mainly affected by non-modifiable factors, such as age and initial comorbidities [20-22]. These are different from those in a specific population of respiratory ECMO patients. Recovery status was associated with ECMO-related factors in 


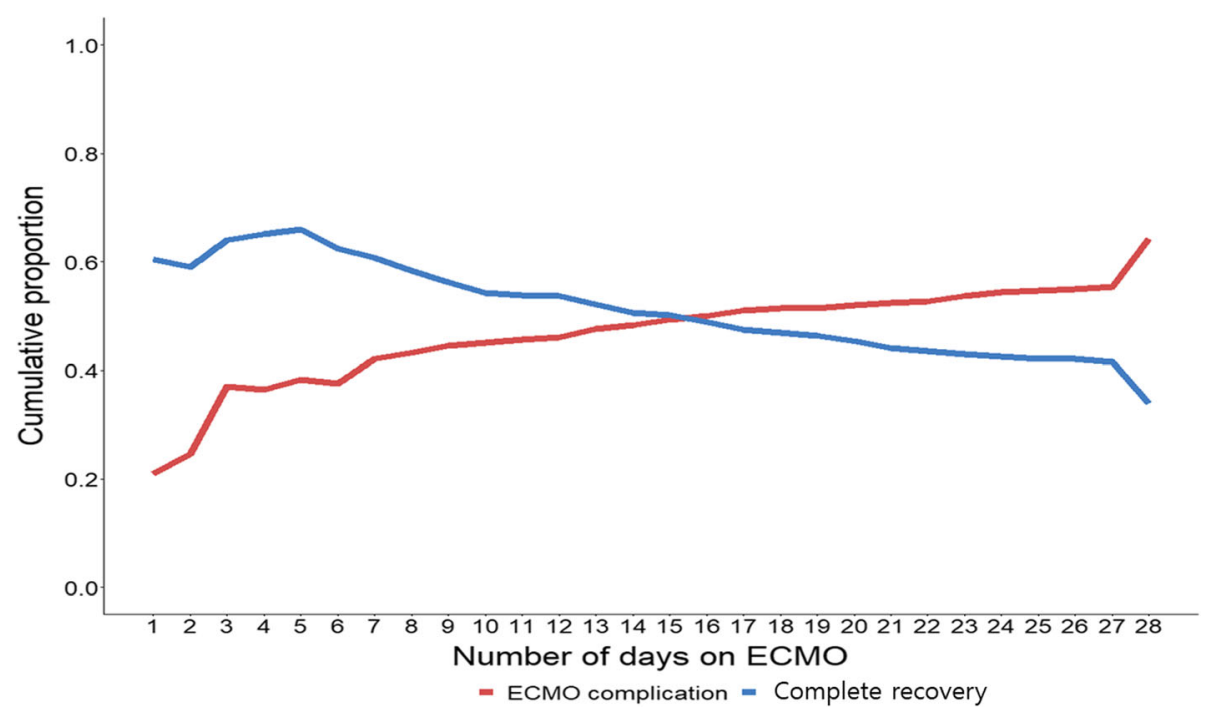

Fig. 2 Cumulative proportion of complete recovery and extracorporeal membrane oxygenation (ECMO) complications according to the ECMO duration

addition to baseline characteristics, such as age and initial severity. In clinical practice, long-term maintenance of ECMO means that the patient's lung recovery is slow, which could be related to the underlying pathology requiring ECMO. However, the extended use of ECMO could inevitably be followed by several ECMO complications, as we and others have found (Fig. 2) [23, 24].

ECMO complications have a significant adverse impact on the long-term prognosis of survivors, failure to wean from ECMO, and early mortality [25-27]. This is a noteworthy point in that ECMO-related complications are potentially modifiable and could be improved. Our findings could be the basis of further improvements in ECMO care by focusing on the reduction of cardiovascular, neurological, and renal complications (Supplement 1).

This study has several limitations. First, this registry relies on voluntary reporting and may have a selection bias with such a heterogeneous group of patients. There are concerns that cases with poor clinical outcomes may be underreported, but this data reflect the clinical course after respiratory ECMO. Secondly, the functional status of the patient after discharge was only estimated on the basis of the discharge locations, and the health-related quality of life or respiratory function of the survivors was not evaluated. Due to limited information from the original registry, the possibility of overestimates of $\mathrm{CR}$ exists. Third, this registry did not include information regarding specific treatments for the primary diagnosis. Therefore, we cannot evaluate the impact of specific treatments for primary diagnosis on patient outcomes. Fourth, this registry did not include information about weaning strategy of ECMO and other adjunctive strategies of mechanical ventilation. Despite these limitations, the main strength of our study is the large scale of the cohort. The long-term maintenance of ECMO and

Table 3 Unfavorable factors for complete recovery after weaning from veno-venous extracorporeal membrane oxygenation (W ECMO)

\begin{tabular}{|c|c|c|c|c|}
\hline \multirow[t]{2}{*}{ Variables } & \multicolumn{2}{|c|}{ Univariate regression } & \multicolumn{2}{|c|}{ Multivariate regression } \\
\hline & OR $(95 \% \mathrm{Cl})$ & $p$ & OR $(95 \% \mathrm{Cl})$ & p \\
\hline Age ( $\geq 65$ years) & $0.81(0.68-0.98)$ & 0.030 & $0.72(0.59-0.87)$ & 0.001 \\
\hline Cardiac arrest before ECMO & $0.79(0.63-0.99)$ & 0.040 & $0.76(0.60-0.96)$ & 0.021 \\
\hline Vasopressor & $0.67(0.59-0.75)$ & $<0.001$ & $0.73(0.64-0.83)$ & $<0.001$ \\
\hline NMB agents & $0.86(0.76-0.96)$ & 0.009 & & \\
\hline RRT before ECMO & $0.34(0.24-0.48)$ & $<0.001$ & $0.40(0.28-0.57)$ & $<0.001$ \\
\hline ECMO-related complication & $0.63(0.56-0.71)$ & $<0.001$ & $0.76(0.67-0.85)$ & $<0.001$ \\
\hline Long-term ECMO support ( $\geq 2$ weeks) & $0.41(0.36-0.47)$ & $<0.001$ & $0.42(0.37-0.48)$ & $<0.001$ \\
\hline
\end{tabular}

$O R$ odds ratio, $\mathrm{Cl}$ confidence interval, ECMO extracorporeal membrane oxygenation, NMB neuromuscular blockade, $R R T$ renal replacement therapy 


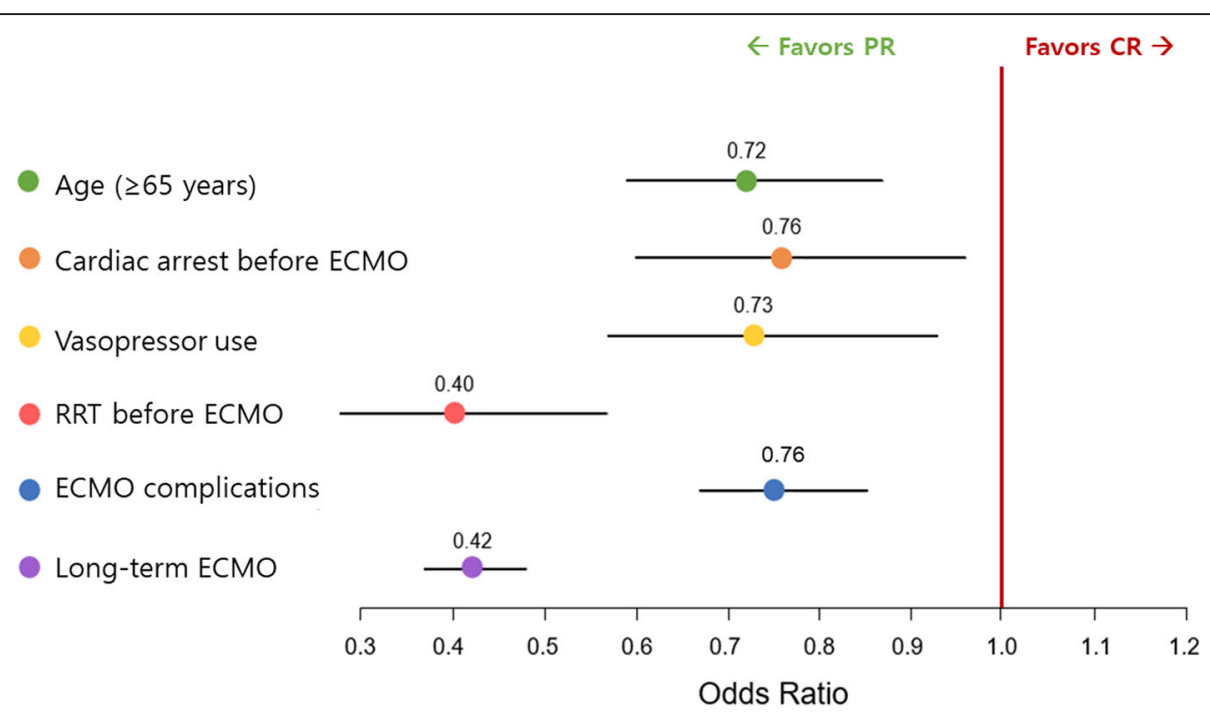

Fig. 3 Logistic regression odds ratios of each factor comparing complete recovery with partial recovery

ECMO complications clearly contribute to worse postweaning outcomes in ECMO survivors. Therefore, clinicians should pay attention to modifiable factors to improve the rate of $\mathrm{CR}$ of patients after ECMO.

\section{Conclusions}

In conclusion, on the basis of a large scale international cohort, a substantial number of patients with severe acute respiratory failure who successfully terminated ECMO did not achieve CR. The overall home discharge rate was only $33.7 \%$, and old age, baseline organ failure, delayed resolution of respiratory dysfunction, and ECMO complications hindered recovery after weaning from ECMO. Future research should focus on the reduction of the modifiable risk factors to facilitate the $\mathrm{CR}$ of patients after ECMO.

\section{Supplementary information}

Supplementary information accompanies this paper at https://doi.org/10. 1186/s40560-020-00480-1.

Additional file 1. Logistic regression odds ratio for complete recovery of each ECMO complication after adjusting for age, severity, and ECMO duration.

\section{Acknowledgements}

We received data from the Extracorporeal Life Support Organization (ELSO) Registry Committee. We thank the ELSO and Peter Rycus for their support. We also appreciate all ELSO centers for their elaborate work and patient assistance.

\section{Authors' contributions}

HY analyzed and interpreted the data. DK and YK were validated the results. HY and WC were major contributors in writing the manuscript. All authors read and approved the final manuscript.

\section{Availability of data and materials} Not applicable

Ethics approval and consent to participate

The analysis was approved by the institutional review board (Pusan National University Yangsan Hospital, 05-2019-135), and the need for informed consent was waived.

\section{Consent for publication}

Not applicable

\section{Competing interests}

The authors report no conflicts of interest.

\section{Author details}

${ }^{1}$ Division of Pulmonary, Allergy, and Critical Care Medicine, Department of Internal Medicine, Pusan National University Yangsan Hospital, Geumo-ro 20, Beomeo-ri, Mulgeum-eup, Yangsan-si, Gyeongsangnam-do 626-770, Republic of Korea. 'Department of Thoracic and Cardiovascular Surgery, Pusan National University Yangsan Hospital, Yangsan, South Korea. ${ }^{3}$ ECMO Registry of the Extracorporeal Life Support Organization (ELSO), Ann Arbor, MI, USA.

Received: 27 April 2020 Accepted: 10 August 2020

Published online: 20 August 2020

\section{References}

1. Bein T, Weber-Carstens S, Apfelbacher C. Long-term outcome after the acute respiratory distress syndrome: different from general critical illness? Curr Opin Crit Care. 2018;24:35-40. https://doi.org/10.1097/MCC. 0000000000000476.

2. Herridge MS, Cheung AM, Tansey CM, Matte-Martyn A, Diaz-Granados N, AlSaidi $F$, et al. One-year outcomes in survivors of the acute respiratory distress syndrome. New Eng J Med. 2003:348:683-93.

3. Cuthbertson BH, Roughton S, Jenkinson D, Maclennan G, Vale L. Quality of life in the five years after intensive care: a cohort study. Crit Care. 2010;14:R6.

4. Desai SV, Law TJ, Needham DM. Long-term complications of critical care. Crit Care Med. 2011:39:371-9.

5. Wang CY, Calfee CS, Paul DW, Janz DR, May AK, Zhuo H, et al. One-year mortality and predictors of death among hospital survivors of acute respiratory distress syndrome. Intensive Care Med. 2014:40:388-96.

6. Herridge MS, Tansey CM, Matte A, et al. Functional disability 5 years after acute respiratory distress syndrome. N Engl J Med. 2011:364:1293-304.

7. McHugh LG, Milberg JA, Whitcomb ME, et al. Recovery of function in survivors of the acute respiratory distress syndrome. Am J Respir Crit Care Med. 1994;150:90-4. 
8. Herridge MS, Moss M, Hough $\mathrm{CL}$, et al. Recovery and outcomes after the acute respiratory distress syndrome (ARDS) in patients and their family caregivers. Intensive Care Med. 2016;42:725-38.

9. Brandstetter S, Dodoo-Schittko F, Brandl M, et al. Ambulatory and stationary healthcare use in survivors of ARDS during the first year after discharge from ICU: findings from the DACAPO cohort. Ann Intensive Care. 2019;9:70

10. Yeo HJ, Koo S, Han JH, et al. Factors associated with death after successful weaning from respiratory extracorporeal membrane oxygenation: a multicenter analysis. ASAIO J. 2020.

11. Schmidt M, Zogheib E, Roze H, et al. The PRESERVE mortality risk score and analysis of long-term outcomes after extracorporeal membrane oxygenation for severe acute respiratory distress syndrome. Intensive Care Med. 2013;39: 1704-13.

12. Knudson KA, Gustafson $C M$, Sadler $L S$, et al. Long-term health-related quality of life of adult patients treated with extracorporeal membrane oxygenation (ECMO): An integrative review. Heart Lung. 2019;48:538-52.

13. von Bahr V, Kalzen $\mathrm{H}$, Frenckner B, et al. Long-term pulmonary function and quality of life in adults after extracorporeal membrane oxygenation for respiratory failure. Perfusion. 2019;34:49-57.

14. Linden $\mathrm{VB}$, Lidegran MK, Frisen $\mathrm{G}$, et al. ECMO in ARDS: a long-term followup study regarding pulmonary morphology and function and health-related quality of life. Acta Anaesthesiol Scand. 2009;53:489-95.

15. Chang WW, Tsai FC, Tsai TY, et al. Predictors of mortality in patients successfully weaned from extracorporeal membrane oxygenation. PLoS One. 2012;7:e42687. https://doi.org/10.1371/journal.pone.0042687.

16. Sertic F, Chavez $L$, Diagne $D$, et al. Predictors of in-hospital mortality and midterm outcomes of patients successfully weaned from veno-arterial extracorporeal membrane oxygenation. J Thorac Cardiovasc Surg. 2019.

17. Huang $M$, Ong BH, Hoo AEE, et al. Prognostic factors for survival after extracorporeal membrane oxygenation for cardiogenic shock. ASAIO J. 2020;66:141-5.

18. Cox CE, Docherty SL, Brandon DH, et al. Surviving critical illness: The acute respiratory distress syndrome as experienced by patients and their caregivers. Crit Care Med. 2009;37:2702-8.

19. Wunsch H, Guerra C, Barnato AE, Angus DC, Li G, Linde-Zwirble WT. Threeyear outcomes for Medicare beneficiaries who survive intensive care. Jama. 2010;303:849-56.

20. Chiumello D, Coppola S, Froio S, Gotti M. What's next after ARDS: Longterm outcomes. Respir Care. 2016;61:689-99.

21. Gayat E, Cariou A, Deye N, Vieillard-Baron A, Jaber S, Damoisel C, et al. Determinants of long-term outcome in ICU survivors: results from the FROG-ICU study. Crit Care. 2018;22:8.

22. Brinkman S, Bakhshi-Raiez F, Abu-Hanna A, de Jonge E, de Keizer NF. Determinants of mortality after hospital discharge in ICU patients: literature review and Dutch cohort study. Crit Care Med. 2013;41:1237-51.

23. Omar HR, Mirsaeidi M, Mangar D, Camporesi EM. Duration of ECMO is an independent predictor of intracranial hemorrhage occurring during ECMO support. ASAIO J. 2016;62:634-6.

24. Oude Lansink-Hartgring A, de Vries AJ, Droogh JM, van den Bergh WM. Hemorrhagic complications during extracorporeal membrane oxygenation The role of anticoagulation and platelets. J Crit Care. 2019;54:239-43.

25. Yeo HJ, Kim D, Jeon D, Kim YS, Rycus P, Cho WH. Extracorporeal membrane oxygenation for life-threatening asthma refractory to mechanical ventilation: Analysis of the Extracorporeal Life Support Organization registry. Crit Care. 2017:21:297.

26. Kim DW, Yeo HJ, Yoon SH, et al. Impact of bloodstream infections on catheter colonization during extracorporeal membrane oxygenation. J Artif Organs. 2016;19:128-33.

27. Yeo HJ, Kim DH, Jeon D, Kim YS, Cho WH. Low-dose heparin during extracorporeal membrane oxygenation treatment in adults. Intensive Care Med. 2015;41:2020-1.

\section{Publisher's Note}

Springer Nature remains neutral with regard to jurisdictional claims in published maps and institutional affiliations.

\section{Ready to submit your research? Choose BMC and benefit from:}

- fast, convenient online submission

- thorough peer review by experienced researchers in your field

- rapid publication on acceptance

- support for research data, including large and complex data types

- gold Open Access which fosters wider collaboration and increased citations

- maximum visibility for your research: over $100 \mathrm{M}$ website views per year

At BMC, research is always in progress.

Learn more biomedcentral.com/submissions 